\title{
الميزان الغذائي الحالي والمستقبلي في دول شرق افريقيا
}

\author{
جراح عبدالقادر أحمد برجس
}

باحث دكتوراه -معهد البحوث والدراسات الأفريقية ودول حوض النيل- جامعة اسوان.

د/طلعت حافظ اسماعيل

استاذ الاقتصاد الزراعي المتفرغ- كلية الزراعة - جامعة اسيوط.

د/احمد ابراهيم عحم أحمد

استاذ الاقتصاد الزراعي المساعد - كلية الزراعة بأسيوط- جامعة الازهر. 
ملخص

نسبة الاكتفاء الذاتي من الحبوب لمنطقة شرق افريقيا بلغت أدنى حد لها حوالي

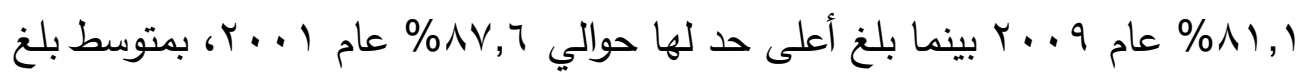
حوالي , >૦\%، وأن نسبة الاكتفاء الذاتي للحبوب لمنطقة شرق افريقيا تناقصت بمعدل غير معنوي احصائياً.

كما اوضحت النتائج: أن نسبة الاكتفاء الذاتي للسكر والمحليات لمنطقة شرق افريقيا

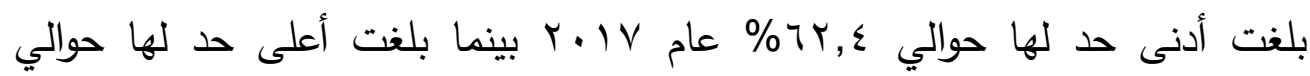

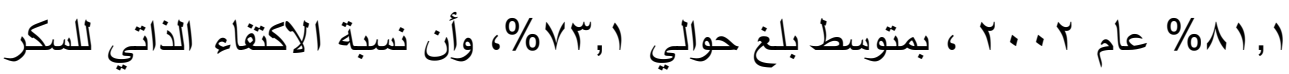
والمحليات لمنطقة شرق افريقيا تناقصت بمعدل معنوي بلغ حوالي 970 ، \% سنويا يعادل حوالي rr, ( \% من متوسط نسبة الاكتفاء الذاتي للسكر والمحليات لمنطقة شرق افريقيا خلال فترة الدراسة. الكلمات المفتاحية: الميزان الغذائي، دول شرق إفريقيا، الاكتفاء الذاتي. Current and Future Food balance in East African Countries

\section{Summary:}

That the rate of self-sufficiency of cereals for the East African region reached its lowest level of about $81.1 \%$ in 2009 , while its 
highest level reached about $87.6 \%$ in 2001, with an average of about $85.1 \%$. Not statistically significant.

The results also showed that the rate of self-sufficiency of meat in the East African region reached its lowest level of about $97.7 \%$ in 2012, while its highest level reached about $99.1 \%$ in 2001, with an average of about $98.3 \%$. East Africa decreased at a significant rate of about $0.068 \%$ annually, equivalent to about $0.07 \%$ of the average rate of self-sufficiency of meat for the East African region during the study period.

The results also showed: that the self-sufficiency rate of fish for the East African region reached its lowest level of about $78.9 \%$ in 2017, while its highest level reached about $87.6 \%$ in 2001, with an average of about $82.2 \%$. East Africa decreased at a significant rate of about $0.43 \%$ annually, equivalent to about $0.52 \%$ of the average rate of self-sufficiency of fish for the East African region during the study period.

When studying the results of the future forecast of the food gap of plant commodities: for grains, the self-sufficiency ratios will reach about $83.2 \%$ in 2025 until they reach a slight decrease to $80.2 \%$ by the year 2050 , and with regard to sugar and sweeteners, the self-sufficiency ratios will reach About 57.7\% in 2025 until it 


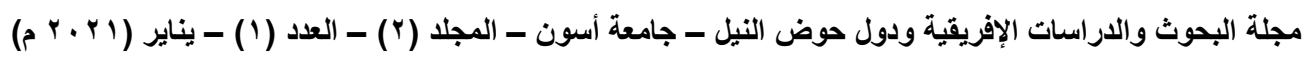

reaches a low of $33.6 \%$ by 2050 , and for vegetable oils, selfsufficiency will reach about $49.1 \%$ in 2025 until it reaches a low of $37.9 \%$ by 2050 .

مقدمة:-

تهتم اغلب دول العالم الفقيره منها والغنيه علي حد سواء بحصول كل افرادها وفي كل الأوقات علي كفايتهم من الغذاء كي يعيشوا حياة نشطة موفورة الصحة، مما يزيد من الاهتماما نحو توفير ذلك الغذاء وخاصة الدول الفقيرة والناميه، وتعمل الدول جاهدة على انتاج أهم المحاصيل الغذائيه كمحاصيل الحبوب كاهم مصادر الغذاء النباتي والعلف الحيواني للإنتاج وتربية الحيوانات بجميع اصنافها لإنتاج اللحوم التي تعتبر من أهم مصادر البروتين الحيواني، وأيضا الأسماك التي تعتبر من الأغذية المطلوبة والغنية بالبروتين وكذلك الزيوت النباتية والحيوانية والسكر باعتبارها أهم مجموعات السلع الغذائية التي تهتم بها موازين الغذاء للدول والاتحادات العالمية.

وتتعاظم أهمية الزراعة في الوقت الراهن في افريقيا ، نظرا لوجود فجوة غذائية لا زالت كبيرة في محاصيل الحبوب الاستراتيجية ، وتعتبر تلك الفجوة ذات تأثير اقتصادي سلبى لدول الاتحاد الافريقي،مما يجعل قضية تأمين الغذاء من أهم الأولويات التي يسعى لها الاتحاد الافريقي، حيث يسعى الي الاهتمام بها والعمل دوما 
علي تضييق تلك الفجوة ، لتقليل الاثار السلبية منها ،بل أن طموحات الدول أخذت بالتزايد لتحقيق الاكتقاء الذاتي من اغلب السلع والمنتجات الغذائية .

وتعتبر دول شرق افريقيا من الدول التي تعاني من فقر نوعي وكمي في السلع الغذائيه المنتجة محليا ، وتضم هذه المنطقة ـ ا دوله هي جزر القمر وجييوتي واريتريا واثيوبيا و كينيا ومدغثقر وموريشيوس و رواندا وسيشيل والصومال وجنوب السودان والسودان وتتزانيا واوغندا.

مثكلة البحث:

رغم المقومات والموارد الطبيعيه التي تحظى بها دول شرق افريقيا، الا أن هذه الدول تعاني فجوة غذائيه في معظم السلع الاستهلاكيه ، وانخفاض نصيب الدستهلك من الانتاج القومي من هذه السلع ، مما يؤدى بالقطع الي أحداث خلل في تحقيق تتميه ورفاهية اقتصاديه في هذه الدول في الوقت الحالي والمستقبلي ، فضلا علي تحمل هذه الدول اعباءا اضافيه في توفير هذا العجز في الميزان الغذائي علي ميزان مدفوعاتها ،الذي يعاني في الاصل من عجز يفوق القدرات الاقتصاديه لهذه الدول. أهداف البحث: 


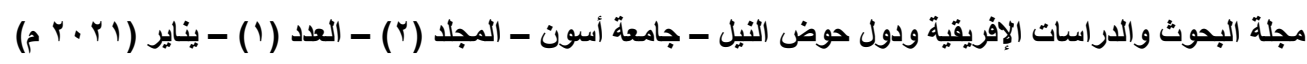

سوف يتناول هذا البحث دراسة الميزان الغذائي لاهم مجموعات السلع الغذائية لدول

شرق افريقيا، لتوضيح الصورة الحقيقية للفجوة والاكتفاء الذاتي لأهم السلع الغذائية حتى يتسنى لأصحاب القرار في هذه الدول تجنب مخاطر الفقر الغذائي والععل على التكامل فيما بينها للوصول الى نسبة مرضية من الاكتفاء الذاتي والامن الغذائي لمواطنيها، وفيما يلي أهم محاور البحث:

1- مؤشرات الانتاج والاستهلاك و والاكتفاء الذاتى لأهم السلع الغذائية في منطقة شرق أفريقيا. r- التصور المستقبلي لمؤشرات الامن الغذائي في منطقة شرق أفريقيا. الاسلوب البحثى ومصادر البيانات:

اعتمدت البحث على التحليل الإحصائي الوصفي والكمي في توضيح مؤشرات الميزان الغذائى لدول شرق افريقيا واستخدام بعض المقاييس الإحصائية لتحقيق أهداف البحث، ولقد اعتمدت البحث على البيانات المنشورة من قبل الجهات العالمية المختصة ، كالبنك الدولي ، وموقع إحصاءات منظمة الاغذية والزراعة (FAO STAT)، وبعض الإصدارات العلمية والجهات المختصة الاخرى. مناقثة النتائج: 
اولاًَ- الفجوة الغذائيه ومدلولها الاقتصادي للدول:

الفجوة الغذائية: هي عبارة عن فجوتين احداهما فجوة ظاهرية وهي تعبر عن مدي الكفاية الكمية لسلعة غذائية معينة أو لسلع الغذاء عموما، لمقابلة احتياجات السكان، في حين تعبر الثانية عن مدي الكفاية الكمية والنوعية ضمن طرق زيادة الإنتاج والاستيراد من الخارج، وكلما زادت هذه الفجوة دل ذلك علي تراجع أوضاع الأمن الغذائي في بلد ما، أما الفجوة الحقيقية هي: عبارة عن الفرق بين ما يحصل عليه الفرد في بلد ما من الغذاء كماً ونوعاً وبين المعايير العلمية الموصي بها والتي وضعتها المنظمات الدولية كمنظمة الصحة العالمية ومنظمة الفاو، حيث أن المعايير قد حدت الكمية اللازمة بالكيلوجرامات، في حين حددت النوعية اللازمة بما يوفره الغذاء من سعرات حرارية وبروتينات ودهون ، فالفرق بين ما يحصل علية الفرد في بلد ما كماً ونوعاً وبين ما حددته المعايير العالمية هو مؤشر لوضع الفجوة الغذائية، كما يعبر مفهوم الإكتفاء الذاتي عن درجة إمكانية بلد ما علي إثباع احتياجات شعبها من إنتاجها المحلي الخاص بها، وهو عبارة عن نسبة كمية الإنتاج الي كمية الإستهلاك كنسبة مئوية، فهو مقياس يعتمد في حسابة علي الكميات دون القيم، وبذلك يتأثر بالأسعار وتقلباتها، وعليه فنسبة الإكتفاء الذاتي الغذائي تعطي انطباعا للإستهلاك، وأكثر واقعية عن حالة الغذاء علي المستوي الدول ، وتبين تاك المؤشرات في الغالب حالة الرفاهية الاقتصاديه الحاليه للدول ، وتعتبر مقياس للعمل علي تحقيق ذلك مستقبلاً.(ربع-r). 
مجلة البحوث والدراسات الإفريقية ودول حوض النيل - جامعة أسون - المجلد (Y) - العدد (l) - يناير ( Y r م م) ثانياً - مؤشرات الانتاج والاستهلاك والاكتفاء الذاتى لأهم السلع الغذائية في منطقة شرق أفربقيا :

أ- مؤشرات الانتاج والاستهلاك والاكتفاء الذاتى لاهم السلع الغذائية النباتية: 1 - مؤشرات الانتاج والاستهلاك والاكتفاء الذاتى من الحبوب:

يوضح الجدول رقم (1) تطور انتاج الحبوب لمنطقة شرق افريقيا خلا الفترة

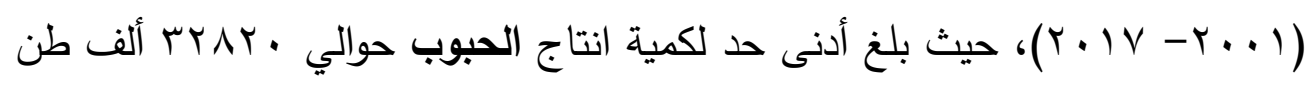

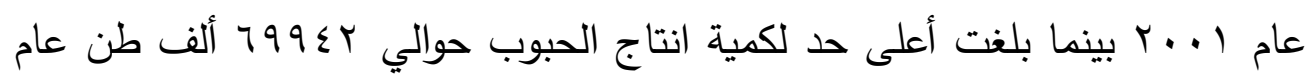

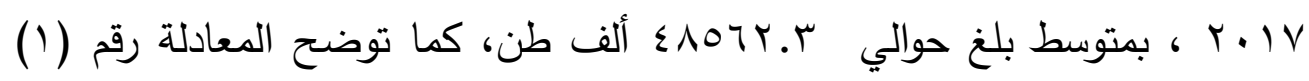
بالجدول رقم (Y) أن كمية انتاج الحبوب لمنطقة شرق افريقيا تزايدت بمعدل معنوي بلغ

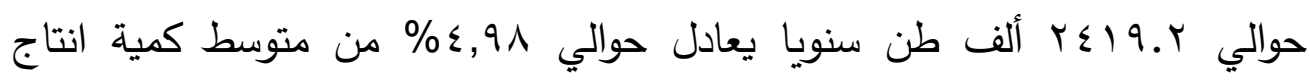
الحبوب خلال فترة الدراسة، ويشير معامل التحديد(R2) إلى أن ^,، 9\% من التغيرات في كمية انتاج الحبوب لمنطقة شرق افريقيا ترجع إلى العوامل التي يعكسها متغير

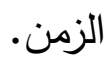

كما يوضح الجدول رقم (1) ان كمية الاستهلاك من الحبوب لمنطقة شرق افريقيا

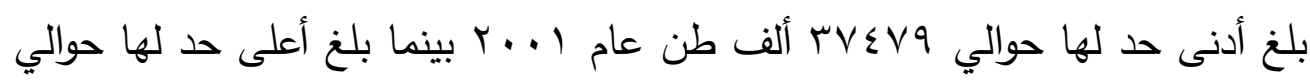

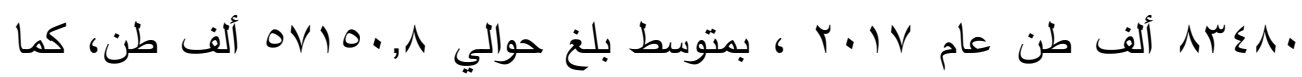


توضح المعادلة رقم (Y) بالجدول رقم (Y) أن كمية استهلاك الحبوب لمنطقة شرق افريقيا تزايدت بمعدل معنوي بلغ حوالي 1.01.01 ألف طن سنويا يعادل حوالي 11 \% من متوسط كمية استهلاك الحبوب 
جدول رقم (1) مؤشرات الانتاج والاستهلاك والاكتفاء الذاتى لاهم السلع الغذائية النباتية لمنطقة شرق افريقيا خلال الفترة

$$
\text { ） ( الوحدة: ألف طن }
$$

\begin{tabular}{|c|c|c|c|c|c|c|c|c|c|c|c|c|}
\hline \multicolumn{4}{|c|}{ الزيوت النباتية } & \multicolumn{4}{|c|}{ السكر والدحليات } & \multicolumn{4}{|c|}{ الحبوب } & \multirow[b]{2}{*}{ ذا } \\
\hline الذاتي(\%تفاء) & الفجوة & الاستهلاك & كمية & الذاتي( الاكتفاء & الفجوة & الاستهلالك & كمية & الاكتفاء & الفجوة & الاستهلاك & كمية & \\
\hline 57.1 & -1001 & 2334 & 1333 & 76.6 & -736 & 3151 & 2415 & 87.6 & -4659 & 37479 & 32820 & 2001 \\
\hline 60.5 & -960 & 2428 & 1468 & 81.1 & -577 & 3056 & 2479 & 86.1 & -5456 & 39254 & 33798 & 2002 \\
\hline 59.7 & -1044 & 2592 & 1548 & 80.0 & -649 & 3244 & 2595 & 83.9 & -6707 & 41636 & 34929 & 2003 \\
\hline 62.3 & -963 & 2554 & 1591 & 79.0 & -729 & 3475 & 2746 & 86.2 & -5806 & 42074 & 36268 & 2004 \\
\hline 59.2 & -1367 & 3351 & 1984 & 79.2 & -738 & 3547 & 2809 & 86.5 & -6036 & 44782 & 38746 & 2005 \\
\hline 55.7 & -1731 & 3909 & 2178 & 77.8 & -838 & 3770 & 2932 & 84.7 & -7308 & 47682 & 40374 & 2006 \\
\hline
\end{tabular}


جراح عبدالقادر أحمد برجس وآخرون، الميزان الغذائي الحالي والمستقبلي في دول شرق افريقيا

\begin{tabular}{|c|c|c|c|c|c|c|c|c|c|c|c|c|}
\hline 57.4 & $|-1678|$ & 3941 & 2263 & 73.4 & -1093 & 4115 & 3022 & 86.9 & $\mid-6249$ & 47660 & 41411 & 2007 \\
\hline 56.5 & -1724 & 3959 & 2235 & 73.6 & -1112 & 4211 & 3099 & 86.5 & -6826 & 50695 & 43869 & 2008 \\
\hline 54.8 & -1884 & 4168 & 2284 & 74.9 & -1043 & 4160 & 3117 & 81.1 & $\begin{array}{c}- \\
10945\end{array}$ & 57807 & 46862 & 2009 \\
\hline 52.6 & -2089 & 4404 & 2315 & 69.8 & -1426 & 4715 & 3289 & 84.9 & -8852 & 58460 & 49608 & 2010 \\
\hline 55.8 & -1834 & 4151 & 2317 & 69.8 & -1449 & 4799 & 3350 & 83.4 & $\begin{array}{c}- \\
10247\end{array}$ & 61901 & 51654 & 2011 \\
\hline 55.1 & -1854 & 4126 & 2272 & 70.8 & -1431 & 4909 & 3478 & 84.7 & -9548 & 62468 & 52920 & 2012 \\
\hline 53.0 & -2358 & 5017 & 2659 & 67.1 & -1795 & 5450 & 3655 & 86.3 & -8816 & 64220 & 55404 & 2013 \\
\hline 54.7 & $-2314 \mid$ & 5108 & 2794 & 71.8 & -1870 & 6621 & 4751 & 85.6 & $\begin{array}{c}- \\
10552\end{array}$ & 73367 & 62815 & 20 \\
\hline
\end{tabular}


مجلة البحوث و الدراسات الإفريقية ودول حوض النيل - جامعة أسون - المجلد (Y) - العدد ( ) - يناير ( ا · r م)

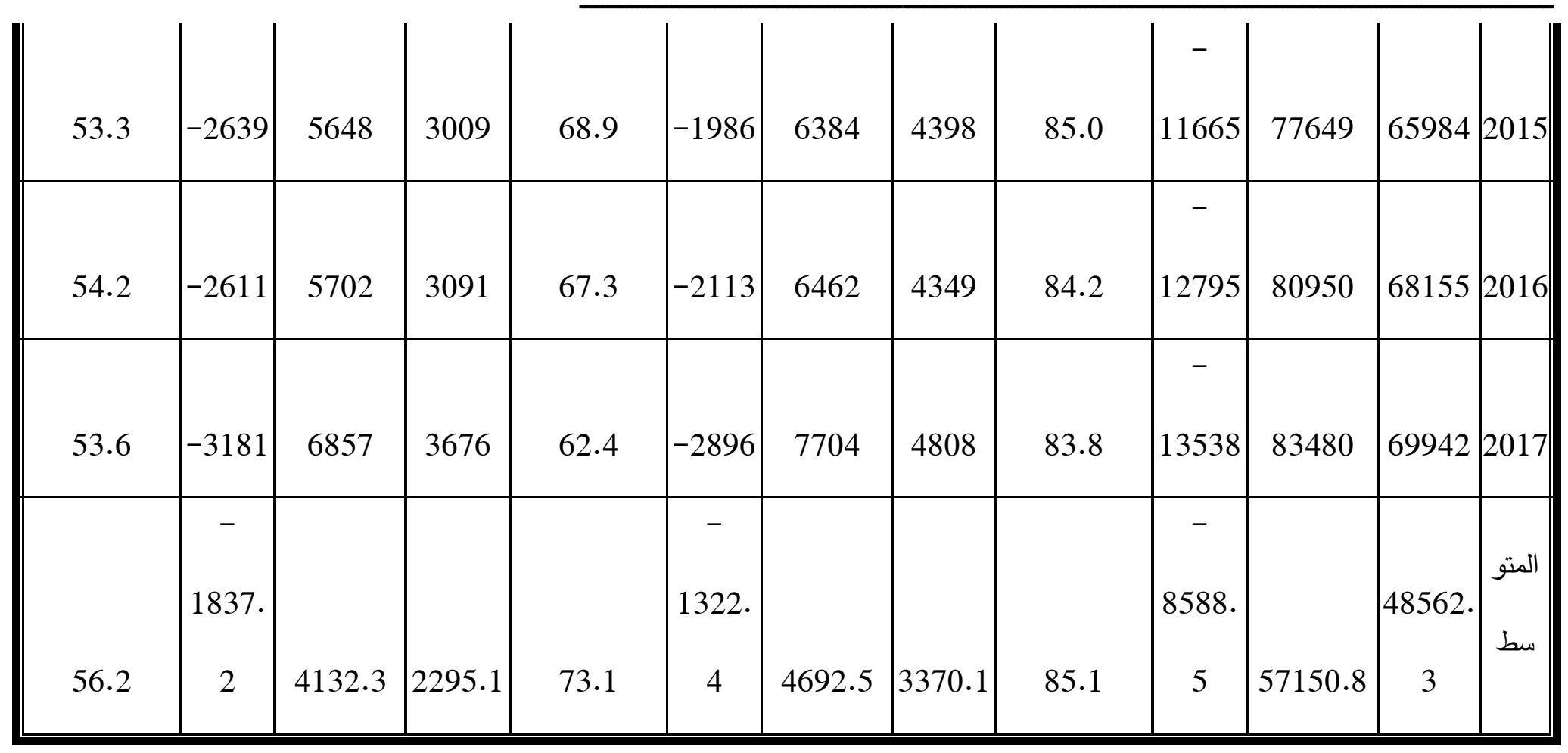

المصدر : جمعت وحسب من: قاعدة بيانات المنظمة العالمية للأغذية والزراعة FAO Stat، . . . . . . 
جدول رقم (r) معادلات الاتجاه الزمني لمؤشرات الانتاج والاستهلاك والاكتفاء الذاتى لمنطقة شرق افريقيا خلال الفترة (1... $(r \cdot 1 \mathrm{~V}$

\begin{tabular}{|c|c|c|c|c|c|c|c|c|}
\hline معدل التغير السنوي المئوي\% | & المتوسط الحسابي & $\mathbf{F}$ & ${ }^{r} \mathbf{R}$ & $\beta$ & $\boldsymbol{\alpha}$ & رقم المعادلة & البيان & السلع الغذائية \\
\hline \multirow{2}{*}{$\varepsilon .91$} & \multirow{2}{*}{ 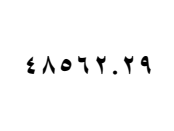 } & \multirow{2}{*}{$* * \varepsilon 04.10$} & \multirow{2}{*}{. .971} & $r \leqslant 19 . r$ & \multirow{2}{*}{ 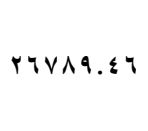 } & \multirow{2}{*}{1} & كمية الإنتاج & \multirow{6}{*}{ الحبوب } \\
\hline & & & & $* * \%(r 1 . r q)$ & & & (ألف طن) & \\
\hline \multirow[b]{2}{*}{0.11} & \multirow[b]{2}{*}{ ovio..1. } & \multirow[b]{2}{*}{$* * \div \leqslant \leq . r 1$} & \multirow[b]{2}{*}{. .978} & rq11..01 & \multirow[b]{2}{*}{ 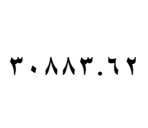 } & \multirow[b]{2}{*}{ r } & كمية الاستهلاك & \\
\hline & & & & $* * *(\Upsilon \cdot . \wedge \varepsilon)$ & & & & \\
\hline \multirow{2}{*}{$. .1 \leq-$} & \multirow{2}{*}{$10.1 \leqslant$} & \multirow{2}{*}{ r. } & \multirow{2}{*}{$. .1 \leqslant \Lambda$} & $. .1 r \mid-$ & \multirow{2}{*}{ מצ.r } & \multirow{2}{*}{$r$} & الاكتفاء الذاتي & \\
\hline & & & & $*(1.71-)$ & & & $(\%)$ & \\
\hline \multirow{3}{*}{$\varepsilon . r q$} & \multirow{3}{*}{ rrv...lr } & \multirow{3}{*}{ 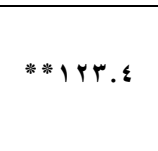 } & \multirow{3}{*}{. . Aqr } & $1 \leqslant \leqslant . \leqslant V$ & \multirow{3}{*}{ r. T9.八T } & \multirow{3}{*}{$\varepsilon$} & كمية الإنتاج & \multirow{5}{*}{ السكر والمحليات } \\
\hline & & & & ***(1) & & & (1) & \\
\hline & & & & $(11.11)$ & & & (الה שט) & \\
\hline \multirow{2}{*}{ אי.7 } & \multirow{2}{*}{ 纟̧ar.or } & \multirow{2}{*}{$* * 17 r .40$} & \multirow{2}{*}{.9917} & Tצ & \multirow{2}{*}{ rrio.91 } & \multirow{2}{*}{ - } & كمية الاستهلاك & \\
\hline & & & & $* *(1$ r.Vq $)$ & & & (ألف طن) & \\
\hline
\end{tabular}


مجلة البحوث و الدراسات الإفريقية ودول حوض النيل - جامعة أسون - المجلا (r) - العدد ( ) - يناير ( Y + r م)

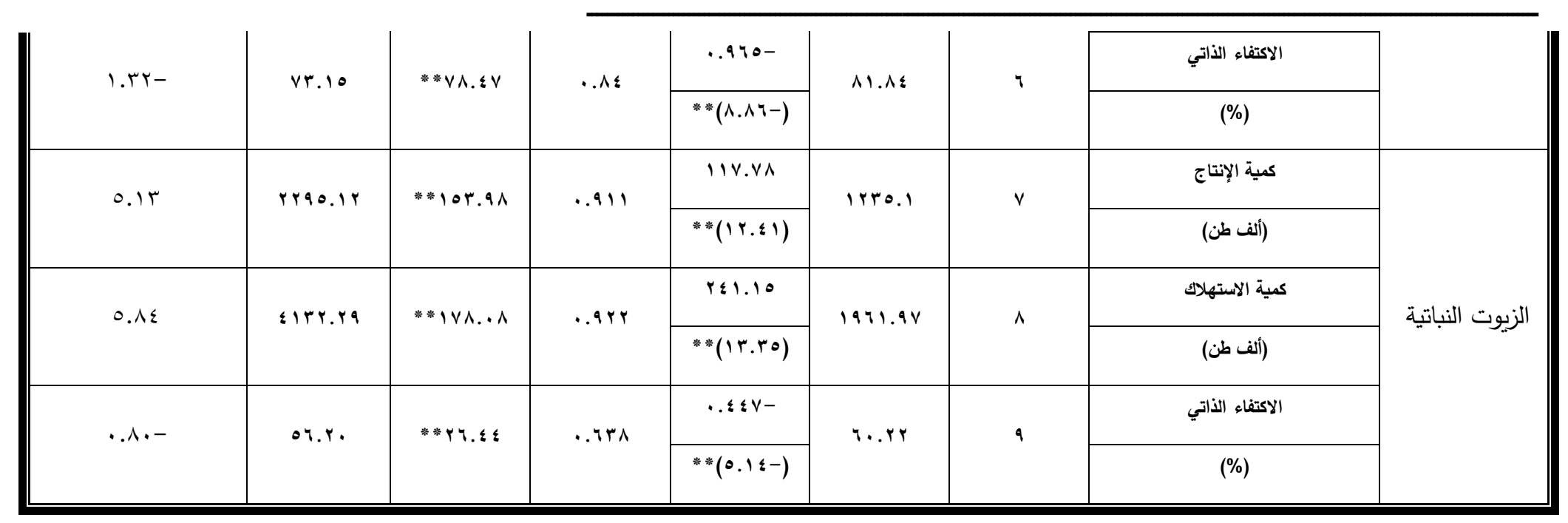

(المصدر : حسب من :جدول رقم (1)

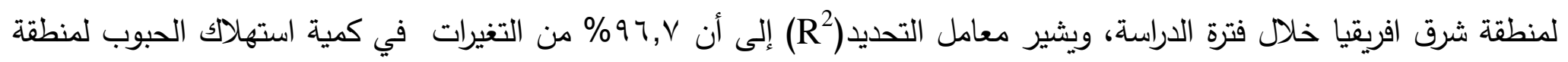
شرق افريقيا ترجع إلى العوامل التي يعكسها متغير الزمن، ومن خلال دراسة كلا من انتاج واستهلاك الحبوب لمنطقة شرق افريقيا لوحظ 


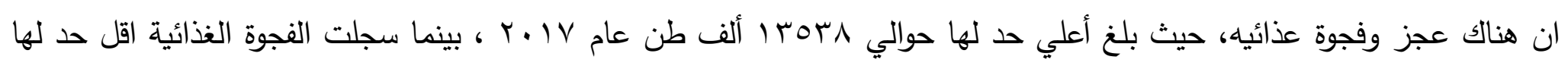
حوالي 709؛ ألف طن عام 1... ، ، بمتوسط بلغ حوالي 1011.0 ألف طن عجز. 


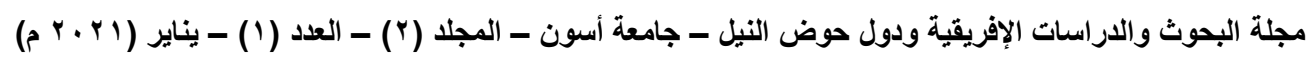

يوضح الجدول رقم (1) ان نسبة الاكتقاء الذاتي للحبوب لمنطقة شرق افريقيا بلغ

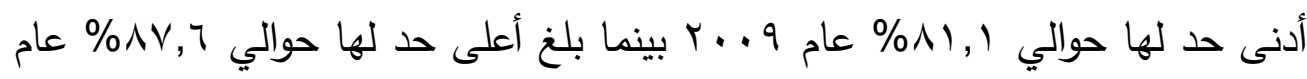

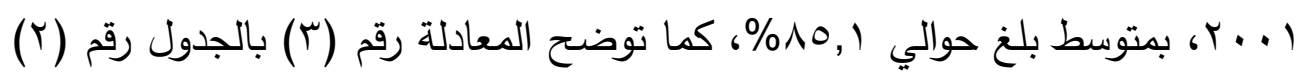
أن نسبة الاكتفاء الذاتي للحبوب لمنطقة شرق افريقيا تتاقصت بمعدل غير معنوي احصائياً.

r- مؤشرات الانتاج والاستهلاك والاكتفاء الذاتى من السكر والمحليات لمنطقة شرق أفريقيا:

يوضح الجدول رقم(1) تطور انتاج السكر والمحليات لمنطقة شرق افريقيا خلا

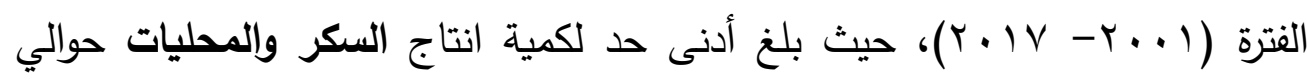

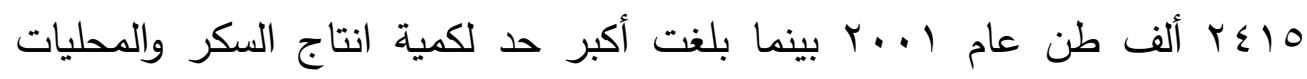

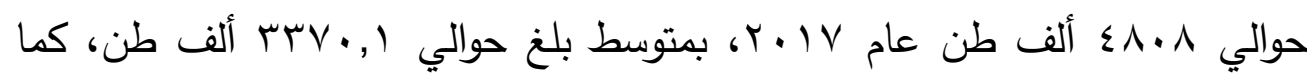
توضح المعادلة رقم (ع) بالجدول رقم (r) أن كمية انتاج السكر والمحليات لمنطقة

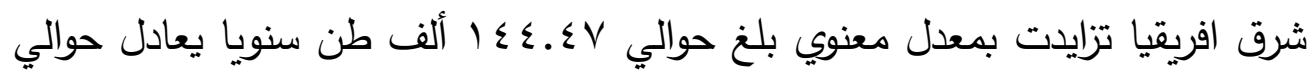
9 §, ٪ من متوسط كمية انتاج السكر والمحليات لمنطقة شرق افريقيا خلال فترة

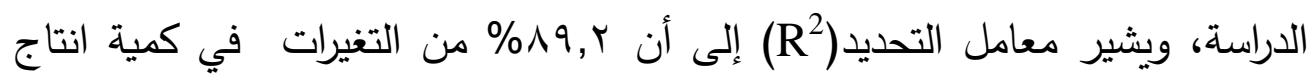
السكر والمحليات لمنطقة شرق افريقيا ترجع إلى العوامل التي يعكسها متغير الزمن. 
يوضح الجدول رقم (1) ان كمية استهلاك السكر والمحليات لمنطقة شرق افريقيا

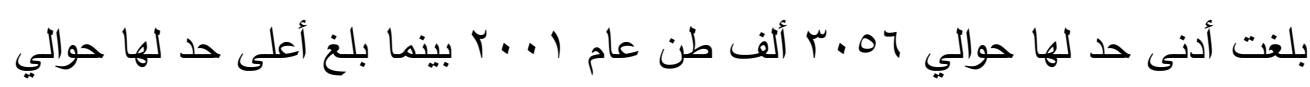

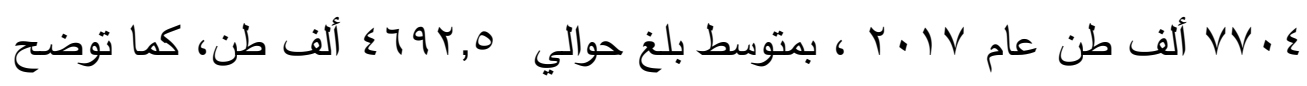
المعادلة رقم (0) بالجدول رقم (r) أن كمية استهلاك السكر والمحليات لمنطقة شرق افريقيا تزايدت بمعدل معنوي بلغ حوالي ج.,ء؟r ألف طن سنويا يعادل حوالي rآ, \% من متوسط كمية استهلاك السكر والدحليات لمنطقة شرق افريقيا خلال فترة

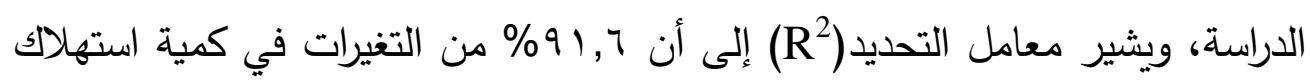
السكر والمحليات لمنطقة شرق افريقيا ترجع إلى العوامل التي يعكسها متغير الزمن، ومن خلال دراسة كلا من انتاج واستهلاك السكر والمحليات لمنطقة شرق افريقيا لوحظ ان هناك عجز وفجوة عذائيه، حيث بلغت أدنى قيمة لها حوالي OVV ألف طن عجز

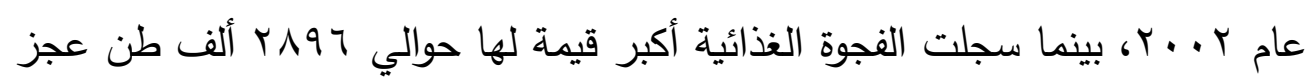

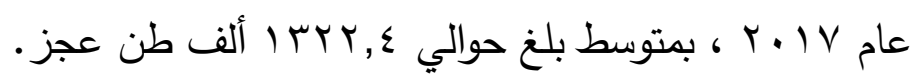

كما يوضح الجدول رقم (1) ان نسبة الاكتفاء الذاتي للسكر والمحليات لمنطقة

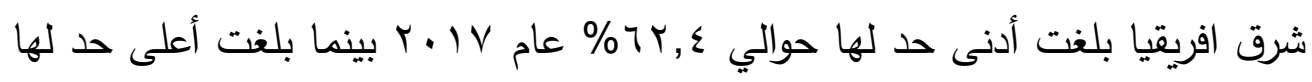

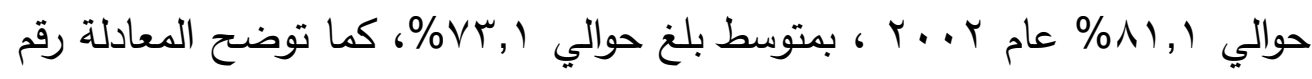
(T) بالجدول رقم (r) أن نسبة الاكتفاء الذاتي للسكر والمحليات لمنطقة شرق افريقيا 
مجلة البحوث والدراسات الإفريقية ودول حوض النيل - جامعة أسون - المجلا (r) - العدد (') - يناير (lY r م)

تتاقصت بمعدل معنوي بلغ حوالي 970 , • سنويا يعادل حوالي بr, ا \% من متوسط نسبة الاكتفاء الذاتي للسكر والمحليات لمنطقة شرق افريقيا خلال فترة الدراسة. ويشير معامل التحديد(R) إلى أن ع^\% من التغيرات في نسبة الاكتفاء الذاتي للسكر والمحليات لهنطقة شرق افريقيا ترجع إلى العوامل التي يعكسها متغير الزمن.

r- مؤشرات الانتاج والاستهلاك والاكتفاء الذاتى للزيوت النباتية في منطقة

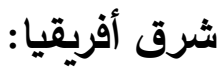

يوضح الجدول رقم (1) تطور انتاج الزيوت النباتيه خلال الفنرة (1...-

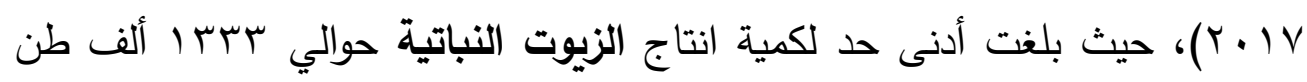

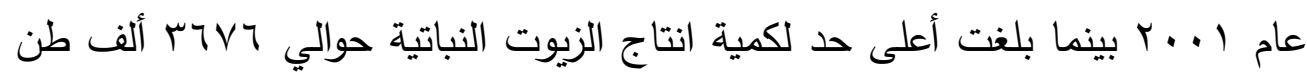

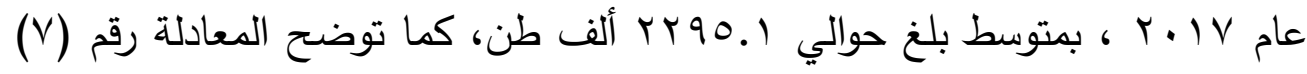
بالجدول رقم (r) أن كمية انتاج الزيوت النباتية لمنطقة شرق افريقيا تزايدت بمعدل

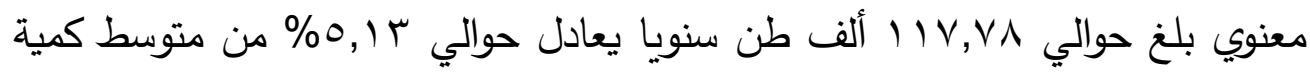
انتاج الزيوت النباتية لمنطقة شرق افريقيا خلال فترة الدراسة، ويشير معامل التحديد(R2) إلى أن ا, 19\% من التغيرات في كمية انتاج الزيوت النباتية لمنطقة شرق افريقيا ترجع إلى العوامل التي يعكسها متغير الزمن. 
ويوضح الجدول رقم (1) ان كمية استهلاك الزيوت النباتية لمنطقة شرق افريقيا

بلغت أدنى حد لها حوالي ع بrr ألف طن عام ال r... ، بينما بلغت أعلى حد لها

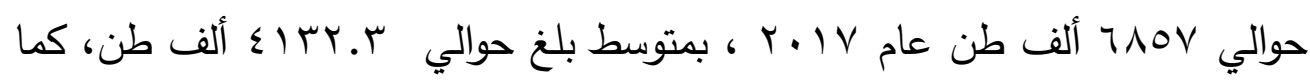
توضح المعادلة رقم (^) بالجدول رقم (؟) أن كمية استهلاك الزيوت النباتية لمنطقة شرق افريقيا تزايدت بمعدل معنوي بلغ حوالي 1 , إr ألف طن سنويا يعادل حوالي £, §, من متوسط كمية استهلاك الزيوت النباتية لمنطقة شرق افريقيا خلا فترة

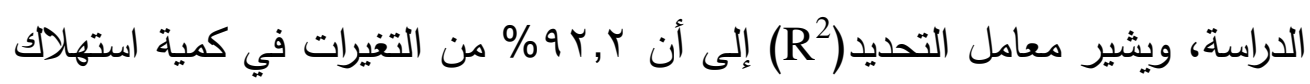
الزيوت النباتية لمنطقة شرق افريقيا ترجع إلى العوامل التي يعكسها متغير الزمن، ومن خلال دراسة كلا من انتاج واستهلاك الزيوت النباتية لمنطقة شرق افريقيا لوحظ ان هناك عجز وفجوة عذائيه ، حيث بلغ أدنى عجز لها حوالي .97 ألف طن عام

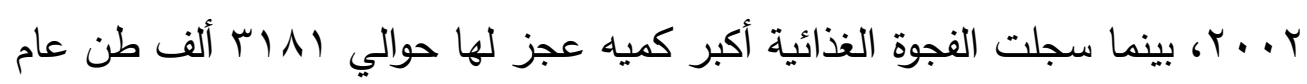

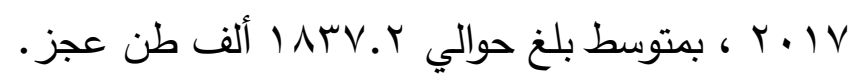
وكما يوضح الجدول رقم (1) ان نسبة الاكتفاء الذاتي للزيوت النباتية لنطقة شرق

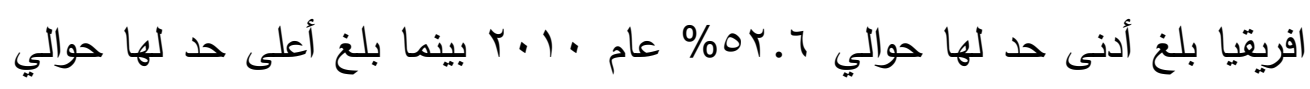

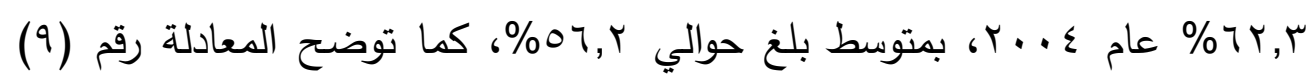
بالجدول رقم (r) أن نسبة الاكتفاء الذاتي للزيوت النباتية لمنطقة شرق افريقيا تناقصت 


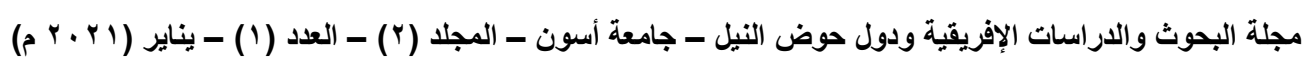

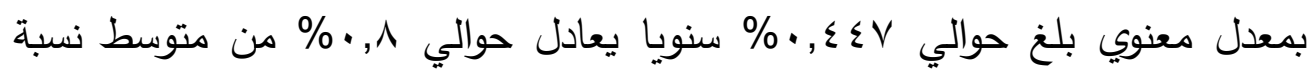
الاكتفاء الذاتي للزيوت النباتية لمنطقة شرق افريقيا خلال فترة الدراسة، ويشير معامل

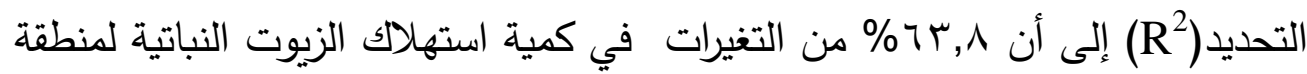
شرق افريقيا ترجع إلى العوامل التي يعكسها متغير الزمن. ب- مؤشرات الانتاج والاستهلاك والاكتفاء الذاتى للسلع الغذائية الحيوانية في منطقة شرق أفريقيا: 1- مؤشرات الانتاج والاستهلاك والاكتفاء الذاتى من اللحوم: يوضح الجدول رقم (r) تطور انتاج اللحوم في منطقة شرق افريقيا خلال الفترة

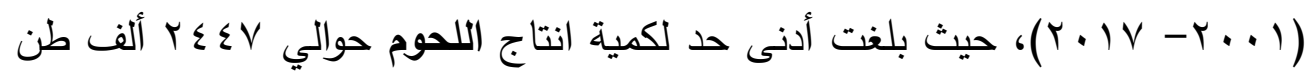

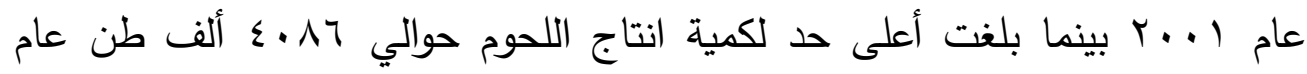

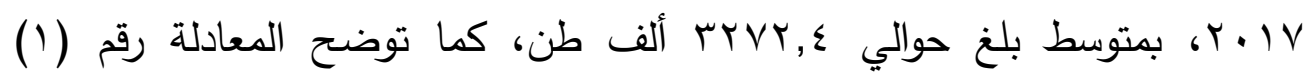
بالجدول رقم (§) أن كمية انتاج اللحوم لمنطقة شرق افريقيا تزايدت بمعدل معنوي بلغ

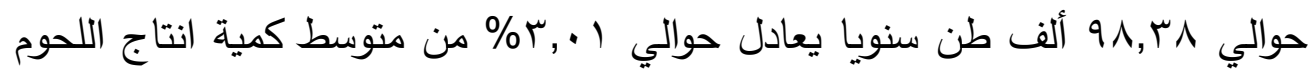

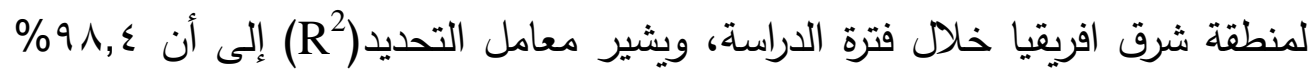
من التغيرات في كمية انتاج اللحوم لمنطقة شرق افريقيا ترجع إلى العوامل التي

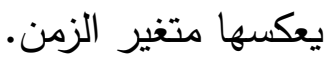


جدول رقم (r) مؤشرات الانتاج والاستهلاك والاكتفاء الذاتى للسلع الغذائية الحيوانية لمنطقة شرق افريقيا خلال الفترة (1 . . -

الوحدة: ألف طن

\begin{tabular}{|c|c|c|c|c|c|c|c|c|}
\hline \multicolumn{4}{|c|}{ الأسماك } & \multicolumn{4}{|c|}{ اللحوم } & \multirow{2}{*}{ السنوات } \\
\hline الاكتفاء الذاتي(\%) & الفجوة & كمية الاستهلاك & كمية الإنتاج & الاكتفاء الذاتي(\%) & 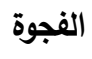 & كمية الاستهلاك & كمية الإنتاج & \\
\hline 87.6 & -133 & 1070 & 937 & 99.1 & -23 & 2470 & 2447 & 2001 \\
\hline 83.9 & -171 & 1065 & 894 & 98.9 & -28 & 2593 & 2565 & 2002 \\
\hline 86.7 & -148 & 1115 & 967 & 99.0 & -26 & 2647 & 2621 & 2003 \\
\hline 84.1 & -214 & 1350 & 1136 & 98.5 & -40 & 2747 & 2707 & 2004 \\
\hline 83.5 & -242 & 1470 & 1228 & 98.5 & -45 & 2930 & 2885 & 2005 \\
\hline 79.7 & -317 & 1558 & 1241 & 98.3 & -52 & 3036 & 2984 & 2006 \\
\hline 83.3 & -278 & 1665 & 1387 & 98.3 & -53 & 3189 & 3136 & 2007 \\
\hline
\end{tabular}


مجلة البحوث و الاراسات الإفريقية ودول حوض النيل - جامعة أسون - المجلا (r) - العدد (') - يناير ( ب • r م)

\begin{tabular}{||c|c|c|c|c|c|c|c|c||}
\hline 80.8 & -308 & 1602 & $\mathbf{1 2 9 4}$ & 98.4 & -53 & 3323 & $\mathbf{3 2 7 0}$ & $\mathbf{2 0 0 8}$ \\
\hline 83.7 & -276 & 1693 & $\mathbf{1 4 1 7}$ & 98.1 & -65 & 3403 & $\mathbf{3 3 3 8}$ & $\mathbf{2 0 0 9}$ \\
\hline 83.1 & -309 & 1832 & $\mathbf{1 5 2 3}$ & 98.2 & -65 & 3541 & $\mathbf{3 4 7 6}$ & $\mathbf{2 0 1 0}$ \\
\hline 81.4 & -372 & 2004 & $\mathbf{1 6 3 2}$ & 97.7 & -82 & 3638 & $\mathbf{3 5 5 6}$ & $\mathbf{2 0 1 1}$ \\
\hline 82.1 & -359 & 2011 & $\mathbf{1 6 5 2}$ & 97.7 & -83 & 3614 & $\mathbf{3 5 3 1}$ & $\mathbf{2 0 1 2}$ \\
\hline 81.3 & -380 & 2033 & $\mathbf{1 6 5 3}$ & 98.4 & -59 & 3658 & $\mathbf{3 5 9 9}$ & $\mathbf{2 0 1 3}$ \\
\hline 79.2 & -512 & 2461 & $\mathbf{1 9 4 9}$ & 98.2 & -70 & 3829 & $\mathbf{3 7 5 9}$ & $\mathbf{2 0 1 4}$ \\
\hline 79.4 & -536 & 2599 & $\mathbf{2 0 6 3}$ & 98.0 & -78 & 3865 & $\mathbf{3 7 8 7}$ & $\mathbf{2 0 1 5}$ \\
\hline 79.0 & -580 & 2759 & $\mathbf{2 1 7 9}$ & 97.8 & -86 & 3969 & $\mathbf{3 8 8 3}$ & $\mathbf{2 0 1 6}$ \\
\hline 78.9 & -580 & 2754 & $\mathbf{2 1 7 4}$ & 98.0 & -84 & 4170 & $\mathbf{4 0 8 6}$ & $\mathbf{2 0 1 7}$ \\
\hline 82.2 & -336.2 & 1825.9 & 1489.8 & 98.3 & -58.4 & 3330.7 & 3272.4 & bug \\
\hline
\end{tabular}

المصدر : جمعت وحسب من: قاعدة بيانات المنظمة العالمية للأغذية والزراعة FAO Stat، .ب.r. 
جدول رقم (؛ ) معادلات الاتجاه الزمني لمؤشرات الانتاج والاستهلاك والاكتفاء الذاتى للسلع الغذائية الحيوانية لمنطقة شرق افريقيا

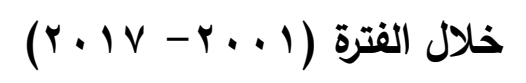

\begin{tabular}{|c|c|c|c|c|c|c|c|c|}
\hline معدل التغير السنوي المئوي\% & المتوسط الحسابي & $\mathbf{F}$ & ${ }^{r} \mathbf{R}$ & $\boldsymbol{\beta}$ & $\boldsymbol{\alpha}$ & رقم المعادلة & البيان البيان & السلع الغذائية \\
\hline \multirow{2}{*}{$r . .1$} & \multirow{2}{*}{ rrVt.ro } & \multirow{2}{*}{ 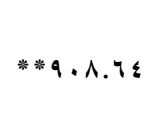 } & \multirow{2}{*}{$. .9 \wedge \leq$} & $9 \wedge . \Lambda$ & \multirow{2}{*}{ rr人я.91 } & \multirow{2}{*}{1} & كمية الإنتاج & \multirow{7}{*}{ اللحوم } \\
\hline & & & & $* *(\mu . .1 \varepsilon)$ & & & (ألف طن) & \\
\hline \multirow{3}{*}{$r . \cdot v$} & \multirow{3}{*}{ וr..vi } & \multirow{3}{*}{ ***^Vะ.Y૫ } & \multirow{3}{*}{. $.9 \wedge r$} & I.r.r & \multirow{3}{*}{$r \leqslant 1 . .09$} & \multirow{3}{*}{ r } & كمية الاستهلاك & \\
\hline & & & & & & & & \\
\hline & & & & $* *($ * $9 . \diamond \vee)$ & & & (ألف طن) & \\
\hline \multirow[b]{2}{*}{$\ldots \vee-$} & \multirow[b]{2}{*}{ qA.r. } & \multirow[b]{2}{*}{ **\%rr.リ } & \multirow[b]{2}{*}{. .719} & $\cdots 41-$ & \multirow[b]{2}{*}{91.91} & \multirow[b]{2}{*}{$r$} & الاكتفاء الذاتي & \\
\hline & & & & $* * *(0 . \vee ฯ-)$ & & & (\%) & \\
\hline \multirow{2}{*}{$0 . \leqslant 7$} & \multirow{2}{*}{$1 \leqslant \wedge 9 . \vee 7$} & \multirow{2}{*}{ **\%ด人.ๆ } & \multirow{2}{*}{$.99 \leqslant$} & M.ru & \multirow{2}{*}{ Vov.vV } & \multirow{2}{*}{$\varepsilon$} & كمية الإنتاج & \multirow{3}{*}{ الأسماك } \\
\hline & & & & $* *(19.9 V)$ & & & (ألف طن) & \\
\hline 0.90 & 11ro.q. & TOY.As &. .909 & 1.1 .7 & $\wedge \leqslant \Lambda .07$ & 0 & كمية الاستهلاك & \\
\hline
\end{tabular}




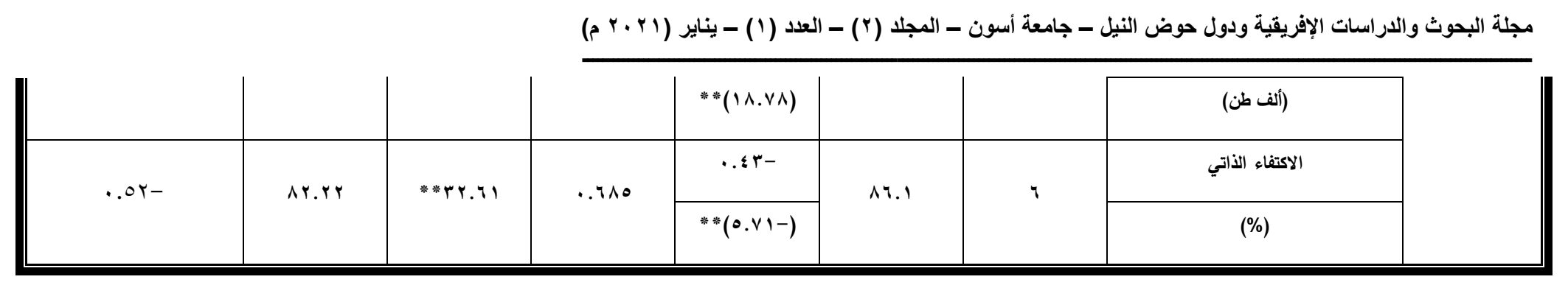

المصدر : حسب من :جدول رقم (ץ) 
يوضح الجدول رقم (r) ان كمية استهلاك اللحوم لمنطقة شرق افريقيا بلغ أدنى

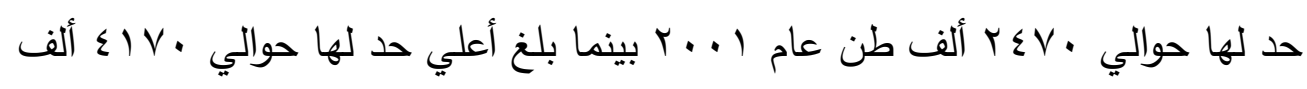

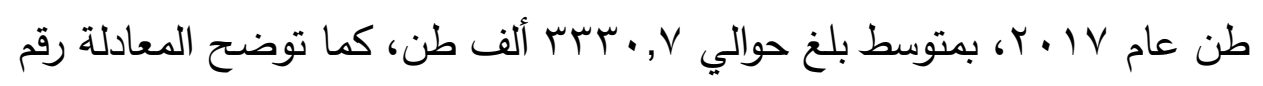
(r) بالجدول رقم (ع) أن كمية استهلاك اللحوم لمنطقة شرق افريقيا تزايدت بمعدل

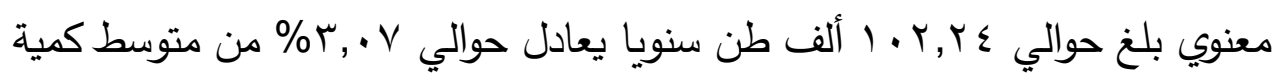
(R²) استهلاك اللحوم لمنطقة شرق افريقيا خلال فترة الدراسة، ويشير معامل التحديد

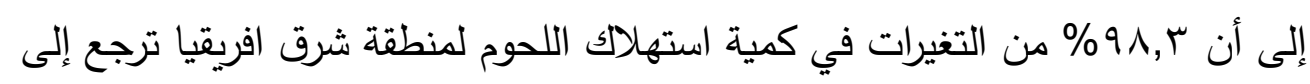
العوامل التي يعكسها متغير الزمن، ومن خلال دراسة كلا من انتاج واستهلاك اللحوم لمنطقة شرق افريقيا لوحظ ان هناك عجز وفجوة غذائيه ، حيث بلغ أدنى حد للفجوة

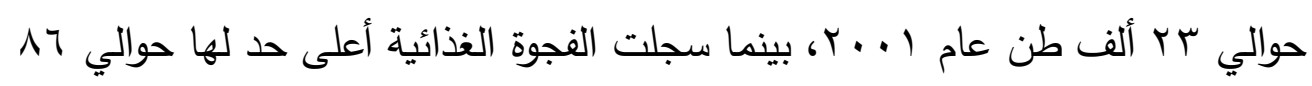

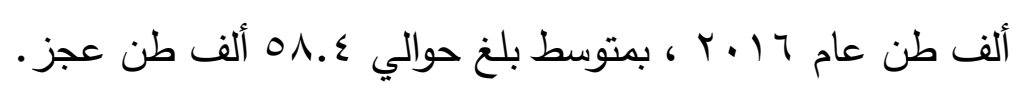

كما يوضح الجدول رقم (r) ان نسبة الاكتفاء الذاتي للحوم لمنطقة شرق افريقيا

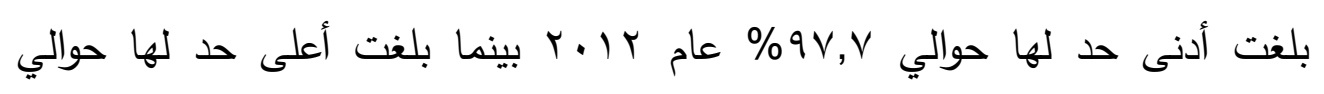

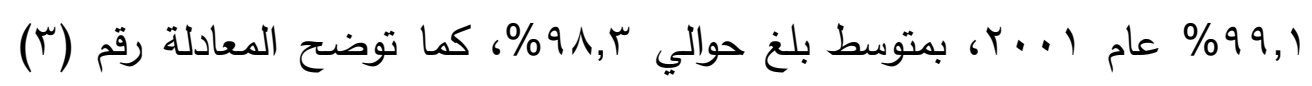
بالجدول رقم (ع) أن نسبة الاكتفاء الذاتي للحوم لهنطقة شرق افريقيا تناقصت بمعدل

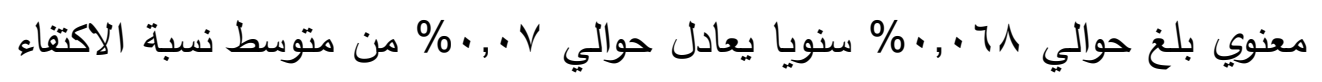




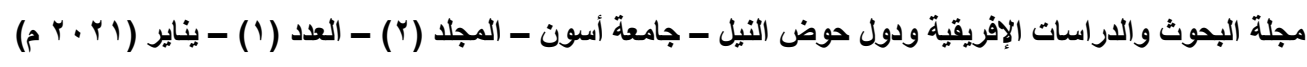

الذاتي للحوم لمنطقة شرق افريقيا خلال فترة الدراسة. ويشير معامل التحديد) إلى

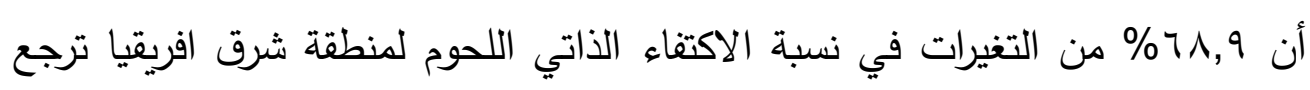
إلى العوامل التي يعكسها متغير الزمن.

r- مؤشرات الانتاج والاستهلاك والاكتفاء الذاتى من الاسماك:

يوضح الجدول رقم (r) تطور انتاج الاسماك لمنطقة شرق افريقيا خلال الفترة

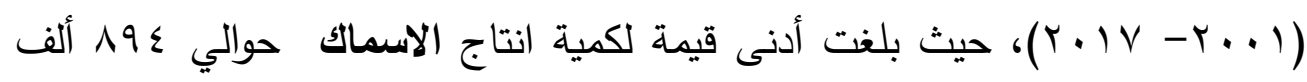

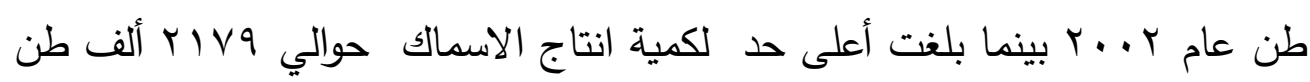

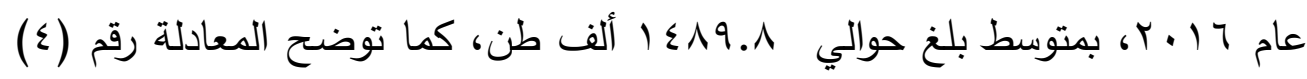
بالجدول رقم (ع) أن كمية انتاج الاسماك لمنطقة شرق افريقيا تزايدت بمعدل معنوي بلغ حوالي بr,1 ألف طن سنويا يعادل حوالي 7 ــ٪\% من متوسط كمية انتاج الاسماك لمنطقة شرق افريقيا خلال فترة الدراسة، ويشير معامل التحديد(R) إلى أن §, 99\% من التغيرات الحادثة في كمية انتاج الاسماك لمنطقة شرق افريقيا ترجع إلى العوامل التي يعكسها متغير الزمن.

يوضح الجدول رقم (r) ان كمية استهلاك الاسماك لمنطقة شرق افريقيا بلغت أدنى حد لها حوالي 10 • 1 ألف طن عام Y .... بينما بلغت أعلى قيمة لها حوالي 


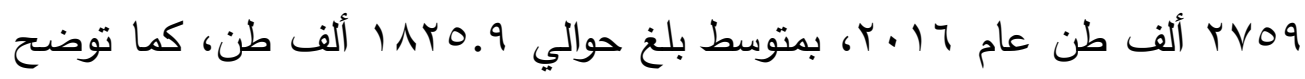
المعادلة رقم (0) بالجدول رقم (ع) أن كمية استهلاك الأسماك ل لمنطقة شرق افريقيا تزايدت بمعدل معنوي بلغ حوالي 1.7 • ألف طن سنويا يعادل حوالي 90,0\% من متوسط كمية استهلاك الاسماك لمنطقة شرق افريقيا خلال فترة الدراسة، ويشير معامل التحديد(R2) إلى أن 90,9\% من التغيرات في كمية استهلاك الاسماك لمنطقة شرق افريقيا ترجع إلى العوامل التي يعكسها متغير الزمن. ومن خلال دراسة كلا من انتاج واستهلاك الاسماك لمنطقة شرق افريقيا لوحظ ان هناك عجز حيث سجلت الفجوة الغذائية أدنى حد لها حوالي بrا ألف طن عام | ...r، بينما سجلت الفجوة الغذائية

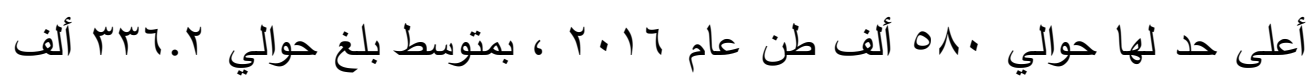

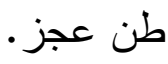

كما يوضح الجدول رقم (r) ان نسبة الاكتفاء الذاتي للأسماك لمنطقة شرق افريقيا

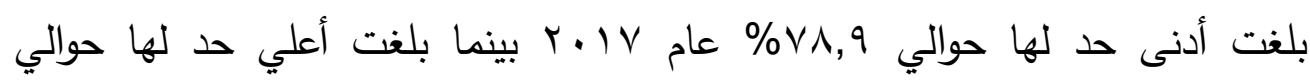

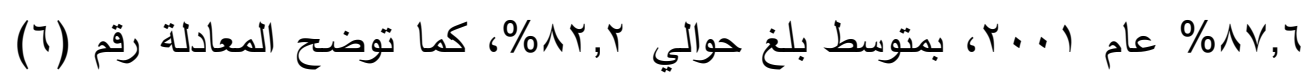
بالجدول رقم (§) أن نسبة الاكتفاء الذاتي للأسماك لمنطقة شرق افريقيا تناقصت

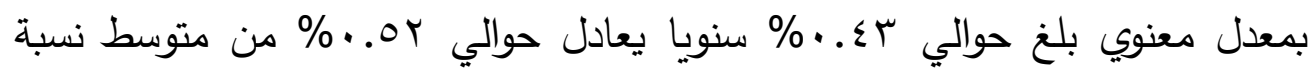
الاكتفاء الذاتي للأسماك لمنطقة شرق افريقيا خلال فترة الدراسة، ويثير معامل 


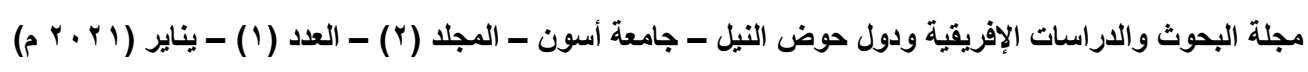

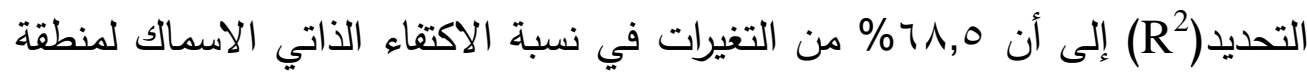
شرق افريقيا ترجع إلى العوامل التي يعكسها متغير الزمن. ثالثاً -التصور المستقبلي لمؤشرات الامن الغذائي في منطقة شرق أفريقيا: أ- الوضع المستقبلي للامن الغذائي من السلع النباتيه: يوضح الجدول رقم (0) الوضع المستقبلي لحالة الامن الغذائي للسلع الغذائية

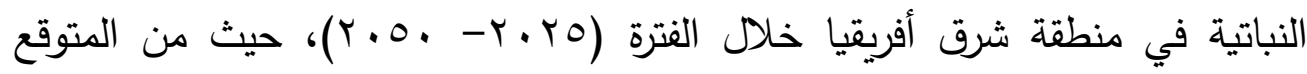
حسب قيم التنبؤ، ان تصل كمية انتاج الحبوب في منطقة شرق أفريقيا الى حوالي

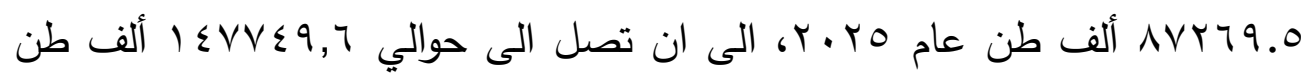

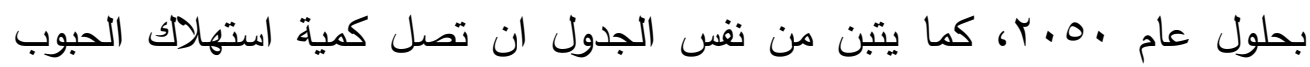

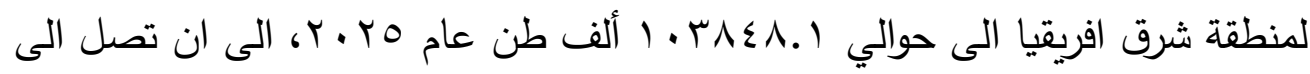

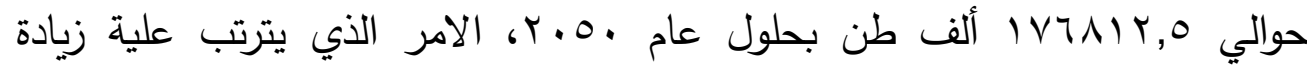

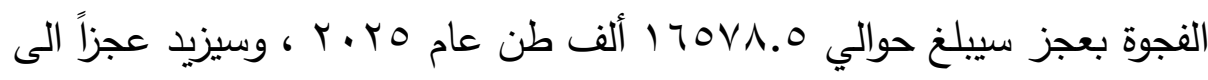




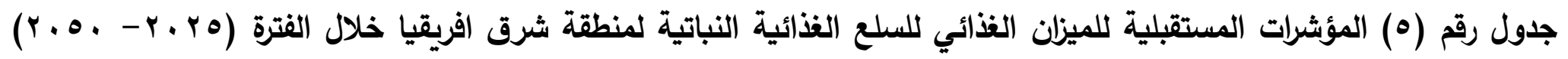

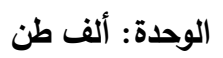

\begin{tabular}{|c|c|c|c|c|c|c|c|c|c|c|c|c|}
\hline \multicolumn{4}{|c|}{ الزيوت النباتية } & \multicolumn{4}{|c|}{ السكر والمحليات } & \multicolumn{4}{|c|}{ الحبوب } & \multirow{2}{*}{ تل } \\
\hline الذاكتفاء & الفجوة & كمية & كمية & الآلاتي(\%) & الفجوة & الاستهلاك & كمية & الذاتي(\%) & الفجوة & كمية الاستهلاك & كمية الإنتاج & \\
\hline 49.1 & $\begin{array}{c}- \\
3811 . \\
0\end{array}$ & $\begin{array}{c}7990 . \\
6\end{array}$ & $\begin{array}{c}4179 \\
.7\end{array}$ & 57.7 & $\begin{array}{c}- \\
3235 \\
8\end{array}$ & $\begin{array}{c}8917 . \\
5\end{array}$ & $\begin{array}{c}5681 \\
.7\end{array}$ & 83.2 & $\begin{array}{c}- \\
16578 \\
.5\end{array}$ & $\begin{array}{c}10384 \\
8.1\end{array}$ & $\begin{array}{c}87269 . \\
5\end{array}$ & $\begin{array}{l}20 \\
25\end{array}$ \\
\hline 46.8 & $\begin{array}{c}- \\
4427 . \\
8\end{array}$ & $\begin{array}{c}9196 . \\
4\end{array}$ & $\begin{array}{c}4768 \\
.6\end{array}$ & 52.9 & $\begin{array}{c}- \\
3833 \\
8\end{array}$ & $\begin{array}{c}10237 \\
.8\end{array}$ & $\begin{array}{c}6404 \\
.1\end{array}$ & 82.6 & $\begin{array}{c}- \\
19075 \\
.4\end{array}$ & $\begin{array}{c}11844 \\
1.0\end{array}$ & $\begin{array}{c}99365 . \\
6\end{array}$ & $\begin{array}{l}20 \\
30\end{array}$ \\
\hline 44.6 & $\begin{array}{c}- \\
5044 .\end{array}$ & $\begin{array}{c}10402 \\
.1\end{array}$ & $\begin{array}{c}5357 \\
.5\end{array}$ & 48.0 & $\begin{array}{c}- \\
4431 .\end{array}$ & $\begin{array}{c}11558 \\
.1\end{array}$ & $\begin{array}{c}7126 \\
.4\end{array}$ & 82.0 & $\begin{array}{c}- \\
21572\end{array}$ & $\begin{array}{c}13303 \\
3.9\end{array}$ & $\begin{array}{c}11146 \\
1.6\end{array}$ & $\begin{array}{l}20 \\
35\end{array}$ \\
\hline
\end{tabular}




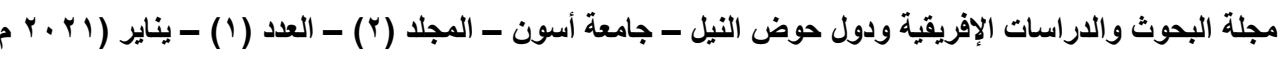

\begin{tabular}{|c|c|c|c|c|c|c|c|c|c|c|c|c|}
\hline & 6 & & & & 7 & & & & .3 & & & \\
\hline 42.3 & $\begin{array}{c}- \\
5661 . \\
4\end{array}$ & $\begin{array}{c}11607 \\
.9\end{array}$ & $\begin{array}{c}5946 \\
.4\end{array}$ & 43.2 & $\begin{array}{c}5029 . \\
6\end{array}$ & $\begin{array}{c}12878 \\
.4\end{array}$ & $\begin{array}{c}7848 \\
.8\end{array}$ & 81.4 & $\begin{array}{c}- \\
24069 \\
.2\end{array}$ & $\begin{array}{c}14762 \\
6.8\end{array}$ & $\begin{array}{c}12355 \\
7.6\end{array}$ & $\begin{array}{l}20 \\
40\end{array}$ \\
\hline 40.1 & $\begin{array}{c}- \\
6278 . \\
2\end{array}$ & $\begin{array}{c}12813 \\
.6\end{array}$ & $\begin{array}{c}6535 \\
.4\end{array}$ & 38.4 & $\begin{array}{c}- \\
5627 . \\
6\end{array}$ & $\begin{array}{c}14198 \\
.7\end{array}$ & $\begin{array}{c}8571 \\
.1\end{array}$ & 80.8 & $\begin{array}{c}- \\
26566 \\
.0\end{array}$ & $\begin{array}{c}16221 \\
9.6\end{array}$ & $\begin{array}{c}13565 \\
3.6\end{array}$ & $\begin{array}{l}20 \\
45\end{array}$ \\
\hline 37.9 & $\begin{array}{c}- \\
6895 . \\
0\end{array}$ & $\begin{array}{c}14019 \\
.3\end{array}$ & $\begin{array}{c}7124 \\
.3\end{array}$ & 33.6 & $\begin{array}{c}- \\
6225 \\
5\end{array}$ & $\begin{array}{c}15519 \\
.0\end{array}$ & $\begin{array}{c}9293 \\
.5\end{array}$ & 80.2 & $\begin{array}{c}- \\
29062 \\
.9\end{array}$ & $\begin{array}{c}17681 \\
2.5\end{array}$ & $\begin{array}{c}14774 \\
9.6\end{array}$ & $\begin{array}{l}20 \\
50\end{array}$ \\
\hline
\end{tabular}

المصدر : حسب اعتمادا على معادلات الاتجاه الزمني العام في جدول رقم(؟). 


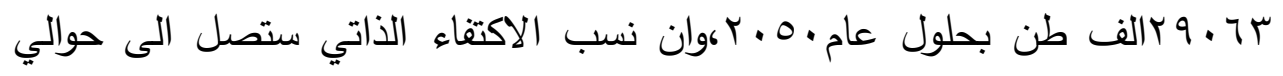

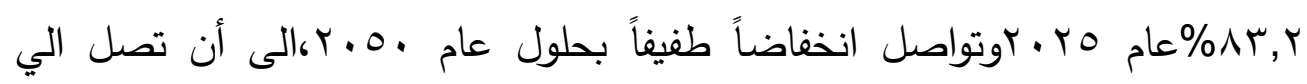

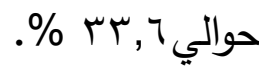

كما يتبين من نفس الجدول انه من المتوقع حسب القيم المتتبئ بها ان تصل كمية

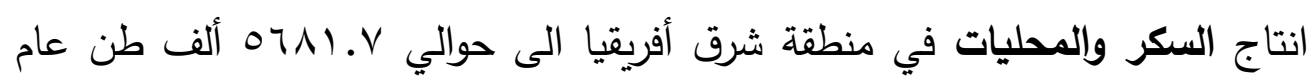

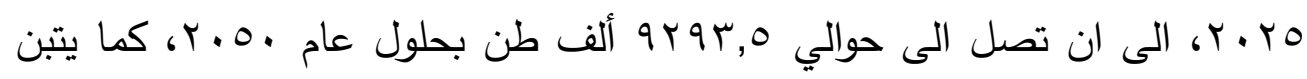
من نفس الجدول ان تصل كمية استهلاك السكر والمحليات لمنطقة شرق افريقيا الى حوالي 191Y,0 ألف طن عام 0. .r، الى ان تصل الى حوالي 10019 ألف طن بحلول عام .Y.O.O، الامر الذي يترتب علية زيادة الفجوة بعزز سيبلغ حوالي

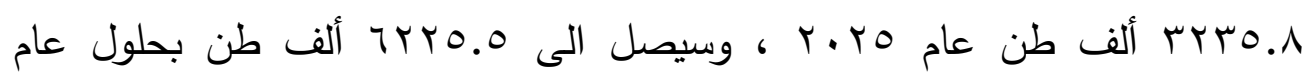

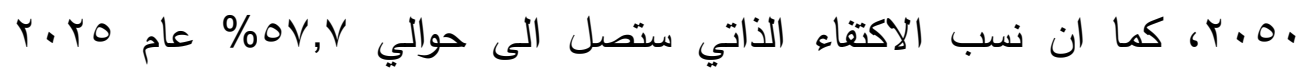

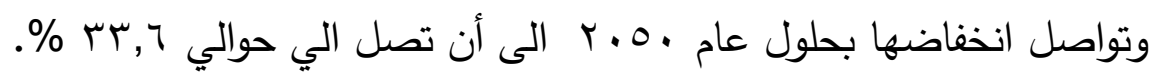

كما يتبين أيضا من نفس الجدول انه من المتوقع حسب قيم التنبؤ ، ان تصل كمية انتاج الزيوت النباتية في منطقة شرق أفريقيا الى حوالي Vq,V ألف طن عام

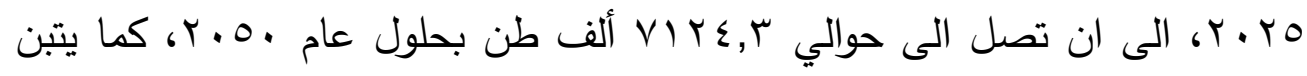


مجلة البحوث والدراسات الإفريقية ودول حوض النيل - جامعة أسون - المجلا (r) - العدد ( ) - يناير (l r r م) من نفس الجدول ان تصل كمية استهلاك الزيوت النباتية لمنطقة شرق افريقيا الى

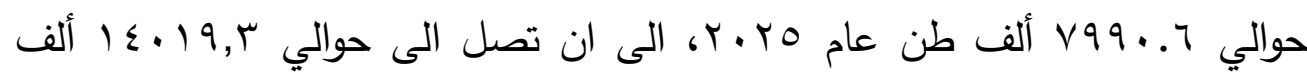
طن بحلول عام •. .ب، الامر الذي يترتب علية زيادة الفجوة بعجز سيبلغ حوالي

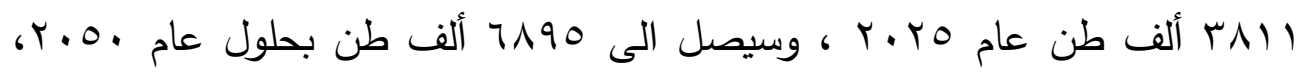

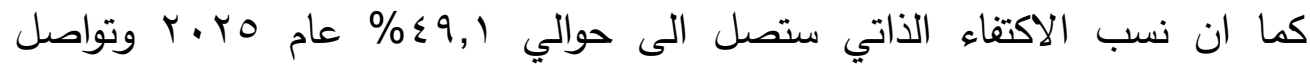

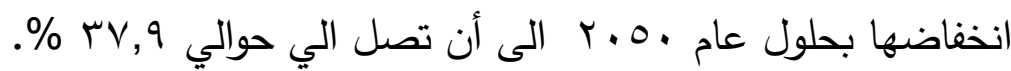

ب- الوضع المستقبلي للامن الغذائي من السلع الحيوانيه:

يوضح الجذول رقم (ך) التصور المستقبلي لحالة الامن الغذائي للسلع الغذائية

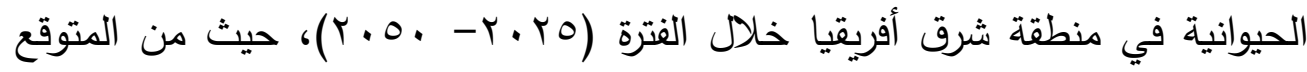
حسب قيم التببئ بها ان تصل كمية انتاج اللحوم في منطقة شرق أفريقيا الى حوالي

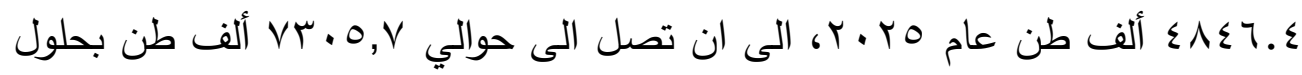
عام •. . . ، كما يتبن من نفس الجدول ان تصل كمية استهلاك اللحوم لمنطقة شرق

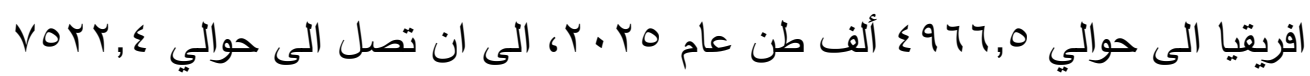
ألف طن بحلول عام •. . r، الامر الذي يترتب علية زيادة الفجوة بعجز سيبلغ حوالي

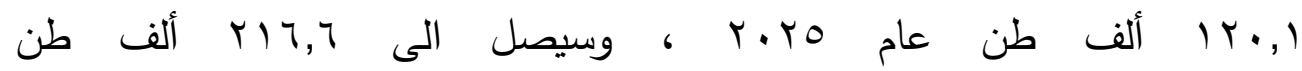


جدول رقم (؟) المؤشرات المستقبلية للميزان الغذائي للسلع الغذائية الحيوانية لمنطقة شرق افريقيا خلال الفترة (ه . r$(r \cdot \odot$. الوحدة: ألف طن

\begin{tabular}{|c|c|c|c|c|c|c|c|c|}
\hline \multicolumn{4}{|c|}{ الأسماك } & \multicolumn{4}{|c|}{ 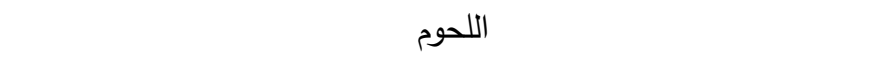 } & \multirow{2}{*}{ ال السنوات } \\
\hline الاكتفاء الذاتي(\%) & الفجوة & كمية الاستهلاك & كمية الإنتاج & الاكتفاء الذاتي(\%) & الفجوة & كمية الاستهلاك & كمية الإنتاج & \\
\hline 75.3 & -772.4 & 3563.5 & 2791.1 & 97.2 & -120.1 & 4966.5 & 4846.4 & 2025 \\
\hline 73.2 & -908.7 & 4106.5 & 3197.8 & 96.9 & -139.4 & 5477.6 & 5338.2 & 2030 \\
\hline 71.0 & -1045.1 & 4649.5 & 3604.4 & 96.5 & -158.7 & 5988.8 & 5830.1 & 2035 \\
\hline 68.9 & -1181.4 & 5192.5 & 4011.1 & 96.2 & -178.0 & 6500.0 & 6322.0 & 2040 \\
\hline 66.7 & -1317.7 & 5735.5 & 4417.8 & 95.8 & -197.3 & 7011.2 & 6813.9 & 2045 \\
\hline
\end{tabular}


مجلة البحوث والدراسات الإفريقية ودول حوض النيل - جامعة أسون - المجلد (r) - العدد (') - يناير ( r r م م)

\begin{tabular}{|l|l|l|l|l|l|l|l|l||}
\hline 64.6 & -1454.0 & 6278.5 & 4824.4 & 95.5 & -216.6 & 7522.4 & 7305.7 & 2050 \\
\hline
\end{tabular}

المصدر : حسب اعتمادا على معادلات الاتجاه الزمني العام في جدول رقم (؛). 


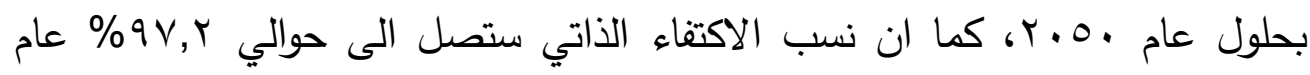

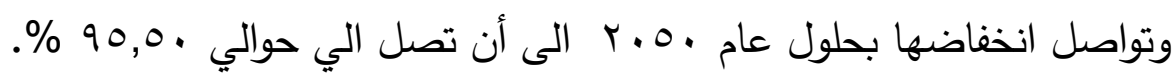

كما يتبين من نفس الجدول انه من المتوقع حسب القيم المتبئ بها ان تصل كمية

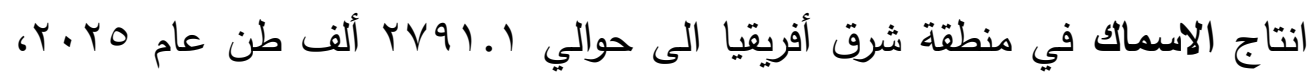

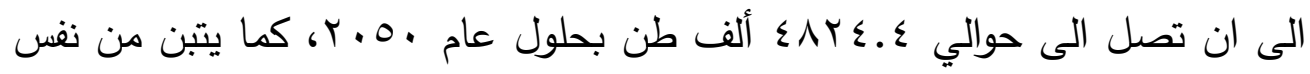
الجدول ان تصل كمية استهلاك الاسماك لمنطقة شرق افريقيا الى حوالي ه.rorr

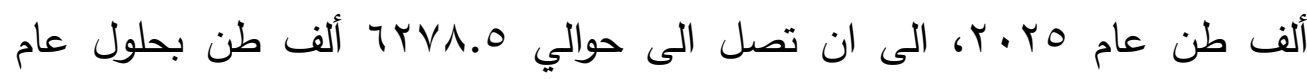
. . . . . الامر الذي يترتب علية زيادة الفجوة بعزز سيبلغ حوالي ؟. ألف طن

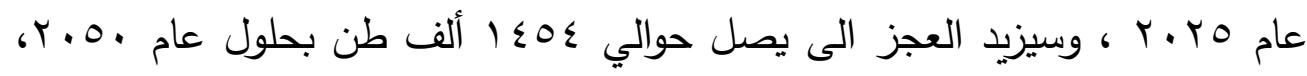
كما ان نسب الاكتفاء الذاتي ستصل الى حوالي ro.r\% عام 0.r.r وتواصل

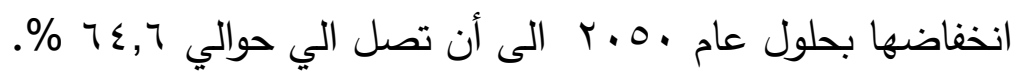

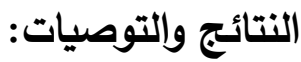

توضح النتائج: أن نسبة الاكتفاء الذاتي من الحبوب لمنطقة شرق افريقيا بلغت

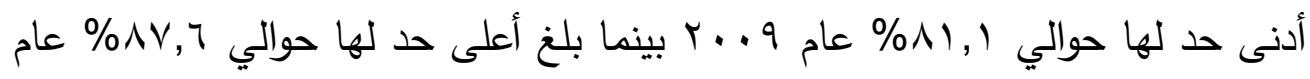


مجلة البحوث والدراسات الإفريقية ودول حوض النيل - جامعة أسون - المجلا (r) - العدد (') - يناير (lY r م)

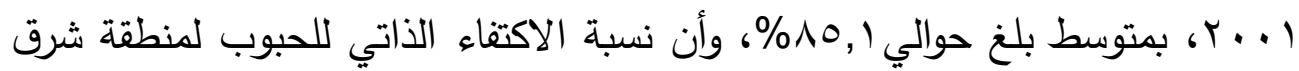
افريقيا تتاقصت بمعدل غير معنوي احصائياً.

كما اوضحت النتائج: أن نسبة الاكتفاء الذاتي للسكر والمحليات لمنطقة شرق افريقيا

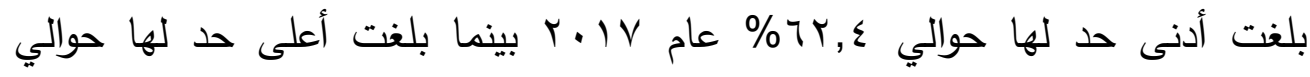

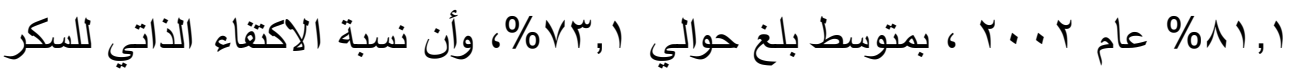
والمحليات لمنطقة شرق افريقيا تناقصت بمعدل معنوي بلغ حوالي 970 •، سنويا يعادل حوالي rr, ( \% من متوسط نسبة الاكتفاء الذاتي للسكر والمحليات لمنطقة شرق افريقيا خلال فترة الدراسة.

وأوضحت النتائج : أن نسبة الاكتفاء الذاتي للزيوت النباتية لمنطقة شرق افريقيا بلغت

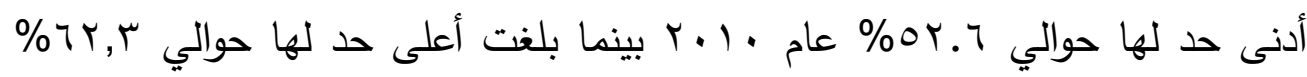

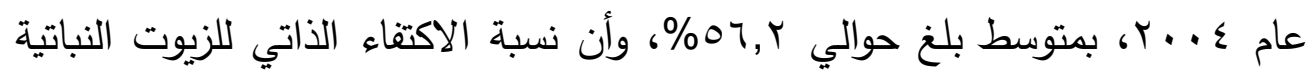

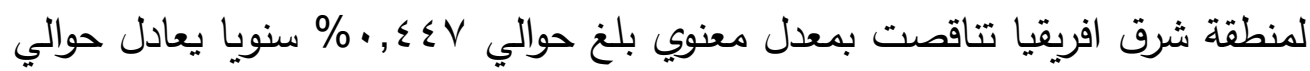
^, • \% من متوسط نسبة الاكتفاء الذاتي للزيوت النباتية لمنطقة شرق افريقيا خلال فترة الدراسة. 
كما بينت النتائج: أن نسبة الاكتفاء الذاتي للحوم لمنطقة شرق افريقيا بلغت أدنى

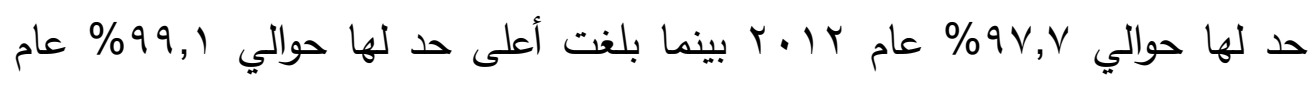

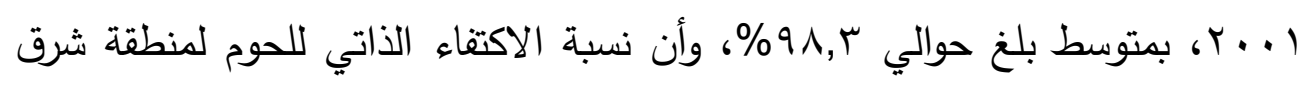

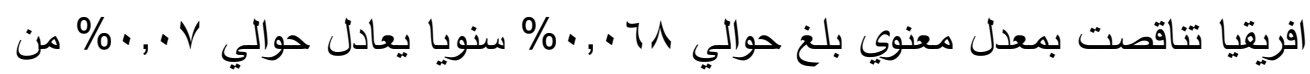
متوسط نسبة الاكتفاء الذاتي للحوم لمنطقة شرق افريقيا خلال فترة الدراسة.

كما أوضحت النتائج : أن نسبة الاكتفاء الذاتي للأسماك لمنطقة شرق افريقيا بلغت

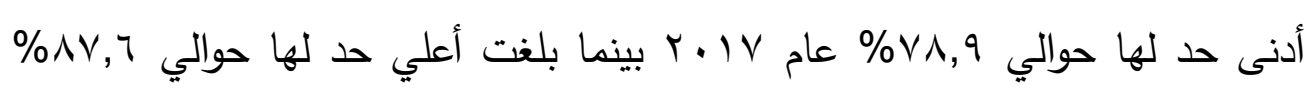

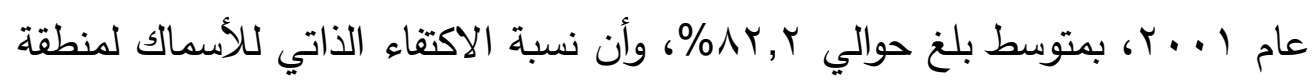
شرق افريقيا تناقصت بمعدل معنوي بلغ حوالي بـع.. \% سنويا يعادل حوالي or. . \% من متوسط نسبة الاكتفاء الذاتي للأسماك لمنطقة شرق افريقيا خلال فترة الدراسة.

وعند دراسة نتائج التنبؤ المستقبلي للفجوة الغذائيه من السلع النباتيه: بالنسبة

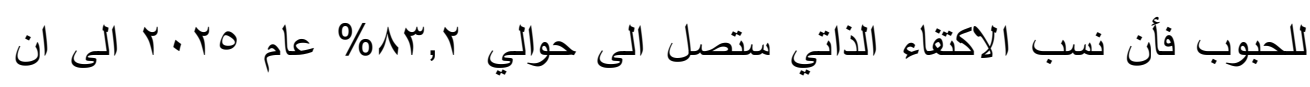

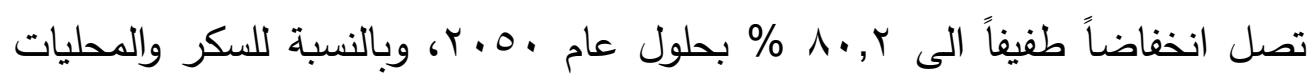

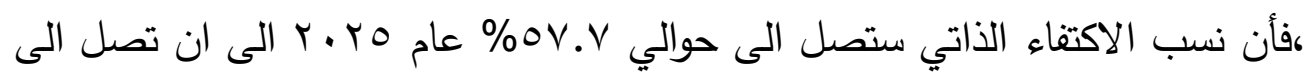




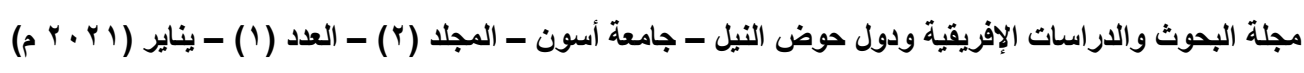

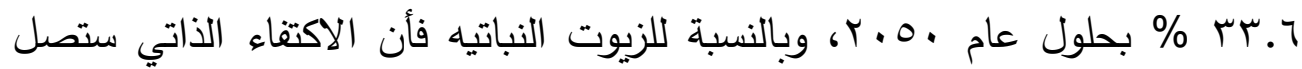

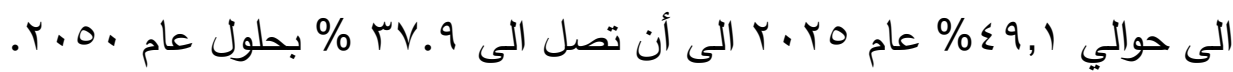
وبدراسة نتائج التنبؤ المستقبلي للفجوة الغذائيه من السلع النباتيه: بالنسبة للحوم

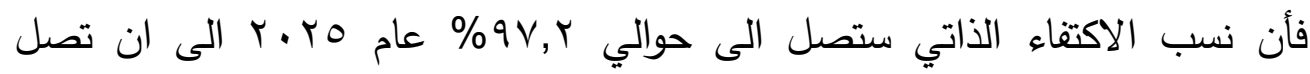

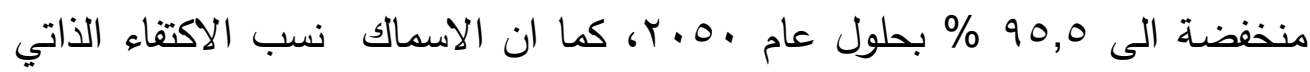

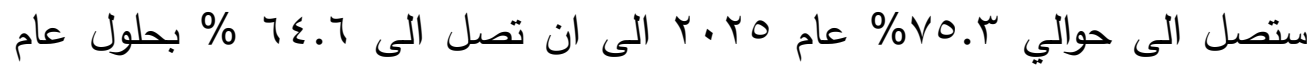
.$r .0$. واستناداً الي النتائج ....يوصى البحث: 1-العمل علي رفع الكفاءة الانتاجيه للسلع النباتيه والحيوانيه، ووكذلك التوسع في الانتاج من تلك السلع ، وذلك للعمل علي سد الفجوة الغذائيه الحاليه ، وتفادي العجز

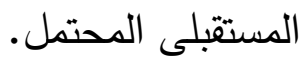
r-التوجة نحو استغلال الموارد الانتاجيه المشتركه بين دول شرق افريقيا ، وذلك للعمل علي زيادة الانتاج ، والاستغلا الاقتصادي لتلك الموارد، وبالتالي رفع الطاقة الانتاجيه الحاليه والمستقبليه للسلع والمنتجات الغذائيه ،خاصة التي توجد بها فجوة 


\section{المراجع العلميه:}

1- أميمــــة سعودي ، القارة الإفريقية .. مستقبل العالم ،الهيئة العامة

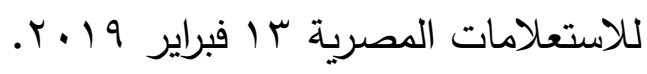

r- ربيع حمح أحمد بلال(دكتور)، احمد سعد محمد راشد(دكتور)، دراسة تحليلية لإمكانية تقليل الفجوة الغذائية من بعض محاصيل الحبوب الإستراتيجية في ظل

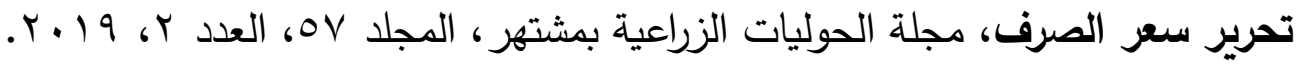
r- صلاح الدين نامق (دكتور) ، اقتصاديات السكان، دار المعارف، القاهرة ، $.19 V$.

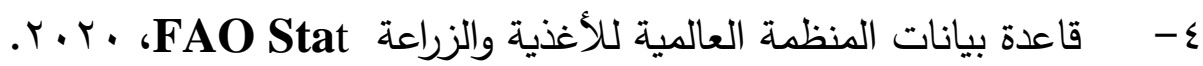

